\title{
A representatividade feminina nos jogos digitais
}

\section{Luciana P. de Araújo Kohler, Leonardo Fronza, Andreza Sartori, Kristhye Burger, Jennyfer Araújo}

\author{
${ }^{1}$ Laboratório de Desenvolvimento e Transferência de Tecnologia (LDTT) \\ Departamento de Sistemas e Computação \\ Universidade Regional de Blumenal (FURB) - Blumenau, SC - Brazil \\ \{lpa, leofronza, asartori, kburger, jennyfera\}@furb.br
}

\begin{abstract}
This paper presents a research did on database Steam platform in relation to digital games with female characters. Observing the first hundred games more played, it was found just 19 games that contain female characters and just one of these games represents $50 \%$ of characters females in relation to total characters. Also, among the analysed games, it was noted that the Battle Arena games are the have most appealing in relation to character female, featuring them with erotic and sexualized images.
\end{abstract}

Resumo. Este artigo apresenta a pesquisa realizada na base de dados da plataforma Steam em relação a personagens femininas nos jogos digitais. A partir dos 100 primeiros jogos mais jogados, encontrou-se apenas 19 jogos que contemplam personagens femininas de modo que somente um deles representa mais de 50\% de personagens femininas em relação ao total. Ainda, dentre os jogos analisados, percebe-se que os jogos no estilo de Battle Arena são os mais apelativos em relação a personagem feminina, caracterizando-as com imagens eróticas e mais sexualizadas.

\section{Introdução}

A indústria de jogos digitais está crescendo cada vez mais e junto a ela pesquisas relacionadas a representatividade de gênero. Isso porque, ainda, os jogos de computador e videogame tem como seu público alvo o gênero masculino de modo que a indústria de jogos represente os personagens envolvidos para o público em questão. Nesse quesito, personagens femininas de forma geral assumem papéis submissas aos personagens masculinos, não representando protagonistas dos jogos.

Ainda, o estereótipo negativo relacionado a mulher se mantém em vários cenários e jogos, representando as personagens com aspectos que se relacionam a sua sexualidade, ao invés de seu intelecto ou comportamento. Dentro desse contexto, a pesquisa em questão tem como objetivo geral traçar o perfil feminino das protagonistas dos jogos digitais.

\section{Revisão Bibliográfica}

A indústria de jogos vem crescendo em termos de entretenimento nos últimos anos de modo que está superando a indústria cinematográfica nesse quesito [Bristot et al. 2017]. Junto a esse fator, se relacionado todos os tipos de jogos, incluindo jogos casuais, onlines e para dispositivos móveis, há um aumento da presença feminina em relação ao 
crescimento da indústria como um todo. Nesse sentido, no Brasil, o público relacionado a todos esses tipos de jogos corresponde a $47 \%$ de jogadores do gênero feminino [de Almeida Gomes da Cruz and Pimenta 2015].

Nesse contexto, o fator público alvo é um exemplo que acaba influenciando na forma como a mulher é representada nos games, visto que são representadas por estereótipos negativos [Bristot et al. 2017]. Os estereótipos muitas vezes são refletidos de forma negativa por gerarem preconceitos e descriminalização por serem ofensivos aos grupos que representam [Izukawa 2015].

Relacionando-se aos jogos de computador e videogames, em sua maioria, os personagens protagonistas ainda são representados pelo gênero masculino, ganhando maior destaque e repercussão [de Almeida Gomes da Cruz and Pimenta 2015]. Apesar da personagem feminina estar inserida nos jogos há bastante tempo, ela não representa a diversidade feminina existente. Na maioria dos jogos, a mulher é representada de forma estereotipada visualmente, sem representatividade em seu comportamento ou físico [de Almeida Gomes da Cruz and Pimenta 2015, Izukawa 2015].

\section{Metodologia}

Para a realização do estudo, utilizou-se o ranking dos 100 jogos digitais mais jogados classificados pela plataforma Steam Database [Steam 2020] até a data de realização da pesquisa que foi em março de 2020.

A partir do ranking, identificou-se o nome do jogo. Em seguida, visitou-se a página oficial do jogo ou a descrição do jogo no próprio portal da Steam para verificar as demais características em busca dos jogos com personagens femininas. Cada jogo que contém personagens femininas foi classificado em relação ao ano de lançamento, colocação no ranking, gênero, quantidade de personagens totais e quantidade de personagens femininas. Para cada personagem feminina, tentou-se encontrar uma foto e suas principais características, tanto físicas, quanto de habilidades.

\section{Resultados alcançados}

A partir dos 100 jogos mais jogados classificados pela plataforma Steam Database datados em março de 2020, encontrou-se apenas 19 jogos que contemplam personagens femininas. Os jogos são apresentados na Tabela 1, contendo o nome do jogo, ano de lançamento, gênero, quantidade de personagens totais e quantidade de personagens femininas.

A partir desta classificação, pode-se observar que somente o jogo The Witcher 3 possui mais personagens femininas que masculinos, sendo que dos 3 personagens principais, 2 são femininos. Observando-se os percentuais de personagens femininas nos jogos em relação a quantidade total de personagens principais, nota-se uma disparidade em relação ao gênero destes, de modo que os que mais se aproximam dos $50 \%$ são Path of Exile e Brawlhalla com um empate de $42,85 \%$ das personagens femininas, seguido por Tom clancy's rainbow six siege com 39,28\%.

Fazendo-se uma análise das personagens femininas destes quatro jogos citados, tem-se as personagens do The Witcher ilustradas na Figura 1. Pode-se notar que são personagens com roupagens conforme a história do jogo, protegidas, possuem armas e ainda mantém suas características femininas como essência, sem serem personagens vulgares 
Tabela 1. Jogos que contemplam personagens femininas

\begin{tabular}{|l|l|l|r|r|r|}
\hline \multicolumn{1}{|c|}{ Jogo } & Ano & \multicolumn{1}{|c|}{ Gênero } & $\begin{array}{c}\text { Total de } \\
\text { personagens }\end{array}$ & $\begin{array}{c}\text { Total } \\
\text { Femininos }\end{array}$ & \% \\
\hline Dota 2 & 2013 & Battle Arena & 119 & 19 & 15,96 \\
\hline Sid Meier's Civilization V & 2010 & 4 X & 43 & 9 & 20,93 \\
\hline Dead by Daylight & 2016 & Survival Horror & 66 & 16 & 24,24 \\
\hline Destiny 2 & 2017 & RPG ação & 4 & 1 & 25 \\
\hline Left 4 Dead 2 & 2009 & Tiro 1 ${ }^{\text {a }}$ pessoa & 8 & 2 & 25 \\
\hline Assassin's Creed Odyssey & 2018 & RPG ação & 11 & 3 & 27,27 \\
\hline Sid Meier's Civilization VI & 2016 & 4 X & 36 & 10 & 27,77 \\
\hline Red Dead Redemption 2 & 2018 & Ação e aventura & 24 & 7 & 29,16 \\
\hline Stardew Valley & 2016 & RPG & 42 & 13 & 30,95 \\
\hline Mount \& Blade: Warband & 2010 & RPG ação & 16 & 5 & 31,25 \\
\hline Smite & 2014 & Battle Arena & 109 & 36 & 33,02 \\
\hline Call of Duty: Black Ops III & 2015 & Tiro 1 ${ }^{\text {a }}$ pessoa & 9 & 3 & 33,33 \\
\hline Paladins & 2016 & Tiro 1 ${ }^{\text {a }}$ pessoa & 45 & 15 & 33,33 \\
\hline Don't Starve Together & - & Aventura & 22 & 8 & 36,36 \\
\hline Monster Hunter: World & 2017 & RPG ação & 16 & 6 & 37,5 \\
\hline $\begin{array}{l}\text { Tom clancy's rainbow } \\
\text { six siege }\end{array}$ & 2015 & Tiro tático & 56 & 22 & 39,28 \\
\hline Brawlhalla & 2014 & Luta & 49 & 21 & 42,85 \\
\hline Path of Exile & 2013 & Hack and slash & 7 & 3 & 42,85 \\
\hline The Witcher 3: Wild Hunt & 2015 & RPG de ação & 3 & 2 & 66,66 \\
\hline
\end{tabular}

ou sexualizadas. Contudo, estas mesmas apresentam em sua roupagem decotes, sendo uma característica comum da representatividade feminina nas personagens.

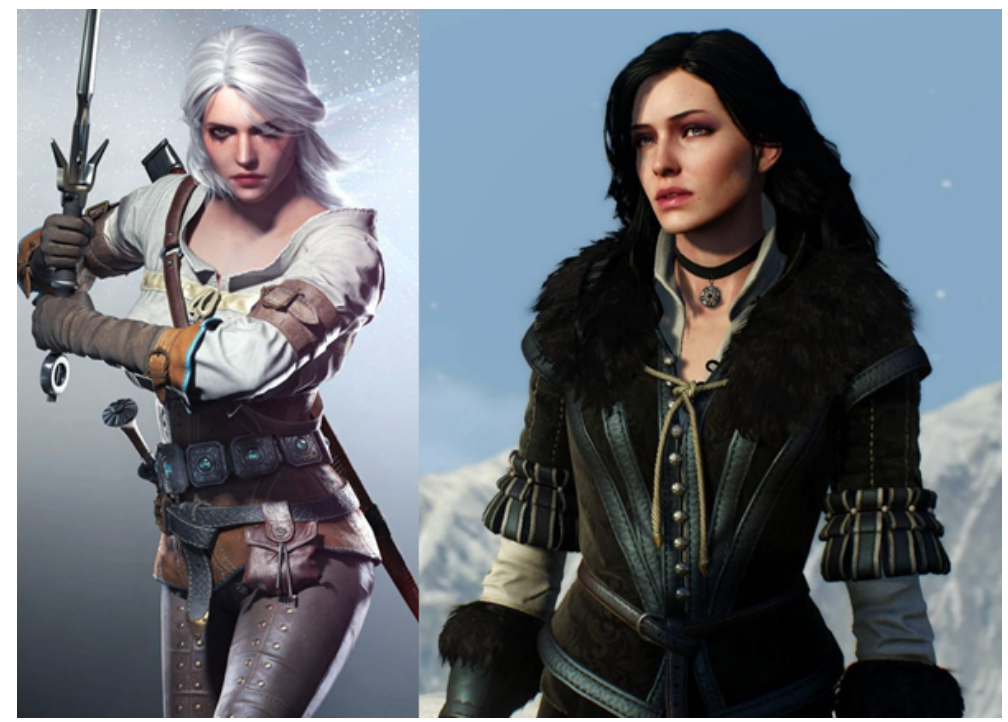

Figura 1. Personagens femininas do jogo The Witcher 3: Wild Hunt [Wallhere 2017]

Observando-se as personagens de Path of Exile, ilustradas na Figura 2, destaca-se 
as roupas coladas, braços de fora e uma delas até mesmo com as pernas de fora (representa uma bruxa poderosa). Contudo, são personagens poderosas no jogo, de modo que a terceira personagem representada só está disponível nas fases finais do jogo.

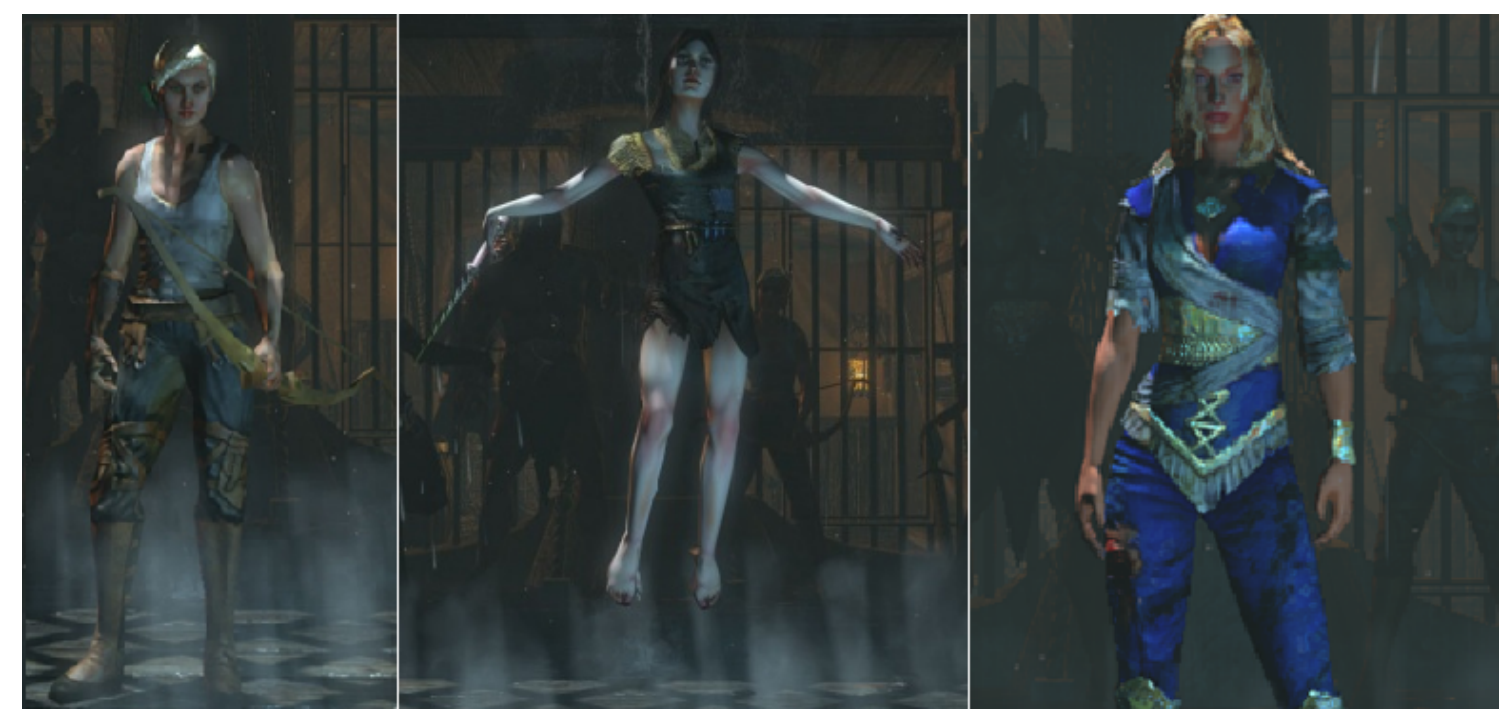

Figura 2. Personagens femininas do jogo Path of Exile

[Fandom Gaming Community 2021]

Em relação as personagens do jogo Brawlhalla, totalizando 21 personagens das 49 existentes, tem-se em primeiro lugar personagens de todos os gêneros, raças e etnias, o que é um ponto interessante do jogo. Contudo, observando-se algumas das personagens percebe-se que várias delas são ilustradas com pouca roupa, pernas ou braços a mostra e decotes. Por outro lado, outras personagens são ilustradas com roupas de proteção e armas. Analisando este jogo de forma geral em relação as personagens, tem-se personagens de diferentes estilos que representa uma grande diversidade tanto de gênero, quanto cultural e de personificação.

Em seguida, analisando-se as personagens do jogo Tom Clancy's Rainbow Six Siege, tem-se novamente uma variedade em sua representatividade feminina tanto em etnias como em personalidades. De forma geral, por ser um jogo de tiro, as personagens possuem seus corpos bem protegidos pelas roupas e são bem armadas. Poucas das personagens possuem braços ou outras partes do corpo de fora. Outro ponto interessante é que, embora estejam protegidas e até de máscaras, suas características femininas são mantidas nos traços do rosto, no olhar e na forma de agir durante o jogo.

Ao fazer uma análise geral das personagens identificadas nos outros jogos, percebeu-se que jogos classificados como Battle Arena tem as personagens femininas mais apelativas, partindo para uma personificação com apelo sexual e erótico maior. Nesses, pode-se perceber que as personagens possuem poucas roupas, tem os seios e outras partes do corpo mais a mostra, assim como roupas mais coladas.

\section{Considerações finais e trabalhos futuros}

Após uma análise dos 100 jogos mais jogados pelo ranking da Steam Database, encontrou-se apenas 19 jogos com personagens femininas, sendo que somente em um 
jogo a quantidade de personagens femininas ultrapassa a quantidade de personagens masculinos. Ao observar as personagens dos jogos, ainda encontra-se várias personagens com apelos sexuais sendo principalmente as de jogos de Battle Arena. Pode-se destacar como um ponto positivo que os jogos de tiro tático estão tomando consciência ao desenhar suas personagens e, estão equipando-as de formas adequadas em sua maioria, semelhante as roupagens dos personagens masculinos, mantendo as características femininas sem levar para apelos eróticos ou sexistas.

Outra questão que deve-se levar em conta é que, várias das personagens femininas possuem fortes poderes nos jogos, e, as vezes, mais poderes que personagens masculinos. Inclusive, em alguns jogos, personagens femininas iniciam com mais vida que personagens masculinos, sendo aí um debate a ser levantado em relação a questões positivas ou negativas relacionadas a temática.

Como trabalhos futuros, pretende-se estudar como jogadores e jogadoras se sentem em relação a sua representatividade nestes personagens. Dessa forma, será possível contribuir de forma social a medida em que o papel da mulher dentro de um jogo digital é representado de modo a identificar além de sua aparência física, seus aspectos comportamentais e intelectuais.

\section{Referências}

Bristot, P. C., Pozzebon, E., and Frigo, L. B. (2017). A representatividade das mulheres nos games. In Proceedings of SBGames 2017, volume 1, pages 862-871.

de Almeida Gomes da Cruz, C. and Pimenta, F. J. P. (2015). Jogos eletrônicos, protagonistas femininas e redução de estereótipos: a série tomb raider. Revista Anagrama: Revista Científica Interdisciplinar da Graduação, 1(9):16p.

Fandom Gaming Community (2021). Official path of exile wiki. Disponível em: https://pathofexile.fandom.com/.

Izukawa, M. (2015). Mulher Entre Espelhos Personagens Femininas Customizáveis nos Videogames. Trabalho de conclusão de curso, Universidade de São Paulo Faculdade de Arquitetura e Urbanismo, Curso de Design. São Paulo.

Steam (2020). Steam database. Disponível em: https://steamdb.info/.

Wallhere (2017). Papel de parede: videogames. Disponível em: https://wallhere.com/. 